\title{
Micropuncture Study of the Effect of Acute Reductions in Glomerular Filtration Rate on Sodium and Water Re- absorption by the Proximal Tubules of the Rat*
}

\author{
Sheldon Glabman, $\uparrow$ Hagop S. Aynedjian, and Norman Bank $\$$ \\ (From the Department of Medicine, New York University School of Medicine, and the Depart- \\ ment of Medicine, Division of Renal Disease, The Mount Sinai Hospital, Nerw York, N. Y.)
}

Although it has been established that sodium reabsorption by the renal tubules occurs by an active transport process and that water follows passively in proportion to sodium (1-3), the factors regulating the rate of reabsorption under various conditions are poorly understood. Micropuncture data in the rat $(4,5)$ and $\operatorname{dog}(6)$ indicate that under normal, nondiuretic conditions, approximately $65 \%$ of the glomerular filtrate is reabsorbed in the first two-thirds of the proximal convoluted tubule. When the filtered load of sodium is increased acutely in rats by hypertonic saline infusion, fractional reabsorption of the glomerular filtrate by the proximal tubules is unchanged ( 7 , 8 ), indicating that an absolute increase in rate of reabsorption occurs. Direct information is lacking on the effect of acute reductions in filtered sodium on tubular reabsorption. Clearance experiments in the dog suggest, however, that an adaptive reduction in sodium transfer occurs, since urine formation does not cease and significant amounts of sodium continue to be excreted even when the glomerular filtration rate (GFR) has been reduced by $40 \%$ (9-11).

In the present micropuncture experiments in rats, the effect of acute reductions in GFR on sodium and water reabsorption by the proximal tubules was determined directly. We found that with reductions in GFR ranging from 10 to $66 \%$, the same fraction of filtered sodium and water was

\footnotetext{
* Submitted for publication February 8, 1965 ; accepted May 10, 1965.

Aided by grants from the National Institutes of Health (HE 05770-04 and AM 08455-01) and the Life Insurance Medical Research Fund.

$\dagger$ Address requests for reprints to Dr. Sheldon Glabman, Department of Medicine, Mount Sinai Hospital, 100th Street and Fifth Avenue, New York, N. Y.

$\ddagger$ Career Scientist of the Health Research Council of the City of New York.
}

reabsorbed by the proximal tubules as under control conditions, indicating that a reduction in the absolute rate of net transfer had occurred. These observations add to the evidence that the filtered load of sodium is an important determinant of the rate of sodium reabsorption by the proximal tubules.

\section{Methods}

Micropuncture studies were performed on 20 white male rats maintained on a regular rat-pellet diet and given tap water ad libitum. Food, but not water, was withheld from individual animals for 16 to 18 hours before the day of study. The methods of anesthesia, surgical preparation, isolation and illumination of the left kidney, and general micropuncture techniques have been described previously (12). In addition to the usual surgical procedures, the abdominal aorta was dissected free of surrounding tissues for about $1 \mathrm{~cm}$ of its length just cephalad to the renal arteries. An iv infusion of $150 \mathrm{mEq}$ per $\mathrm{L}$ sodium chloride was administered at 0.039 or $0.051 \mathrm{ml}$ per minute in 18 experiments and at $0.097 \mathrm{ml}$ per minute in 2 experiments. GFR was measured with inulin- $\mathrm{C}^{\mathbf{1 4}}$ carboxylic acid, ${ }^{1} 25 \mu \mathrm{c}$ as a priming dose and $25 \mu \mathrm{c}$ per hour added to the infusion. It has been found that in the rat, recovery of $\mathrm{C}^{14}$-inulin in the urine after injection into the proximal tubule is essentially complete (13). We assume, therefore, that $\mathrm{C}^{14}$-inulin clearance in these experiments accurately measured GFR. A period of at least 40 minutes was allowed after the inulin prime for inulin equilibration. Blood for inulin concentration was obtained from the cut end of the tail in heparinized capillary tubes at approximately 45-minute intervals during the experiment and the value at the mid-point of tubular fluid and urine collections determined from the blood curve. Urine was collected under oil through a polyethylene catheter secured in the left ureter and volume determined by the change in weight of the collection vial. Radioactivity in blood, tubular fluid, and urine was measured in a Tri-Carb liquid scintillation counter by a method described by Windhager and Giebisch (1). All tubular puncture sites were localized by filling the nephron with a colored latex suspension and at the end of the ex-

\footnotetext{
1 New England Nuclear Corp., Boston, Mass.
} 
TABLE I

Effect of acute reduction in GFR on proximal filtrate reabsorption*

\begin{tabular}{|c|c|c|c|c|c|c|c|c|}
\hline Time & v & $\mathrm{U} / \mathrm{P}_{\mathrm{I}_{\mathrm{n}}}$ & GFR/kidney & $\begin{array}{c}\% \mathrm{Re}- \\
\text { duction } \\
\text { in GFR }\end{array}$ & $T F / P_{I_{n}}$ & $\begin{array}{l}\% \text { Fil- } \\
\text { trate re- } \\
\text { absorbed }\end{array}$ & $\begin{array}{l}\text { Loca- } \\
\text { tion }\end{array}$ & $\mathrm{UNaV}_{\mathrm{Na}}$ \\
\hline $\min$ & $\mu l / \min / k g$ & & $\mathrm{ml} / \mathrm{min} / \mathrm{kg}$ & & & & $\% P$ & $\mu E q / \min / k g$ \\
\hline$\underset{78-153}{0}$ & $7.1^{\text {Infu }}$ & $: \underset{293}{\mathrm{NaC}}$ & $\begin{array}{c}150 \underset{2 \mathrm{mEq}}{2.08} \\
\end{array}$ & L; inulin & ${ }^{4}, \begin{array}{c}4.2 \mu \mathrm{c} \\
1.55\end{array}$ & $\begin{array}{c}\mathrm{ml} \text { at } \\
36\end{array}$ & $\mathrm{ml}_{35}$ pe & $\begin{array}{r}\text { ninute } \\
2.03\end{array}$ \\
\hline $\begin{array}{c}154 \\
155-213\end{array}$ & 8.5 & 210 & 1.79 & $\begin{array}{c}\text { Aorta } c \\
14\end{array}$ & $\begin{array}{r}\text { tricted } \\
2.07 \\
1.49\end{array}$ & $\begin{array}{l}52 \\
33\end{array}$ & $\begin{array}{l}44 \\
31\end{array}$ & 1.24 \\
\hline $\begin{array}{c}214 \\
215-254\end{array}$ & 7.5 & 186 & $1.40^{\mathrm{Ao}}$ & $\begin{array}{l}\text { ic constr } \\
33\end{array}$ & $\begin{array}{c}\text { ion incre } \\
1.68 \\
1.59\end{array}$ & $\begin{array}{l}41 \\
37\end{array}$ & $\begin{array}{l}45 \\
45\end{array}$ & 1.20 \\
\hline
\end{tabular}

* Abbreviations: $\mathrm{V}=$ rate of urine flow; $\mathrm{U} / \mathrm{P}_{\mathrm{In}}=$ urine/plasma inulin ratio; $\mathrm{GFR}=$ glomerular filtration rate; $\mathrm{TF} / \mathrm{P}_{\mathrm{In}_{\mathrm{n}}}=$ tubular fluid/plasma inulin ratio; $\mathrm{U}_{\mathrm{Na}} \mathrm{V}=$ rate of urinary sodium excretion; $\% \mathrm{P}=$ per cent of total length of proximal tubule.

periment dissecting the individual tubules. The location of the puncture site was expressed as a per cent of the total length of the proximal tubule. Blood was obtained from the abdominal aorta at the end of each experiment for sodium determination. Serum and urine sodium concentrations were measured by flame photometry, with lithium as internal standard. Tubular fluid sodium concentrations were measured in 14 samples collected before the application of an aortic clamp and in 10 samples collected after the clamp had been applied. The ultramicro flame photometer used for the tubular fluid sodium measurements was that described by Malnic, Klose, and Giebisch (14). Plasma inulin was corrected for plasma water content of 0.94 , and the corrected values were used to calculate inulin clearance, tubular fluid/plasma inulin $\left(\mathrm{TF} / \mathrm{P}_{\mathrm{In}}\right)$ ratios, and per cent filtrate reabsorbed $[(1-$ $\left.\left.P / T_{\text {In }}\right) \times 100\right]$. Serum sodium was not corrected for plasma water content or a Donnan factor since these tend to cancel one another.

Two experimental protocols were followed. In 9 experiments a control urine and 1 or 2 tubular fluid samples were collected during a 60 - to 120 -minute period.
A metal constricting clamp was then applied to the abdominal aorta above the origin of the renal arteries, and several additional tubular fluid and urine samples were collected. In four experiments, the aorta was constricted immediately after the inulin equilibration period in order to obviate any possible effect of a prolonged saline infusion on proximal sodium and water reabsorption. At least one urine and several tubular fluid collections were made with the clamp in place, the clamp was then removed, and additional urine and tubular fluid samples were obtained. In the remaining 7 experiments, the aorta was constricted after control collections had been obtained, but the clamp proved to be too tight and anuria resulted, or too loose so that GFR fell less than $10 \%$. Therefore, only the control data from these experiments have been included.

In 16 of the experiments, tubular fluid flow rates in individual nephrons were determined by carefully timing the collections of fluid and measuring the volume of the sample in a constant-bore capillary tube of known internal diameter. GFR per nephron was calculated from the expression $T F / P_{\text {In }} \times T F$ flow per minute, and the values were corrected to a standard body weight of $1 \mathrm{~kg}$.

TABLE II

Effect of acute reduction in GFR on proximal filtrate reabsorption

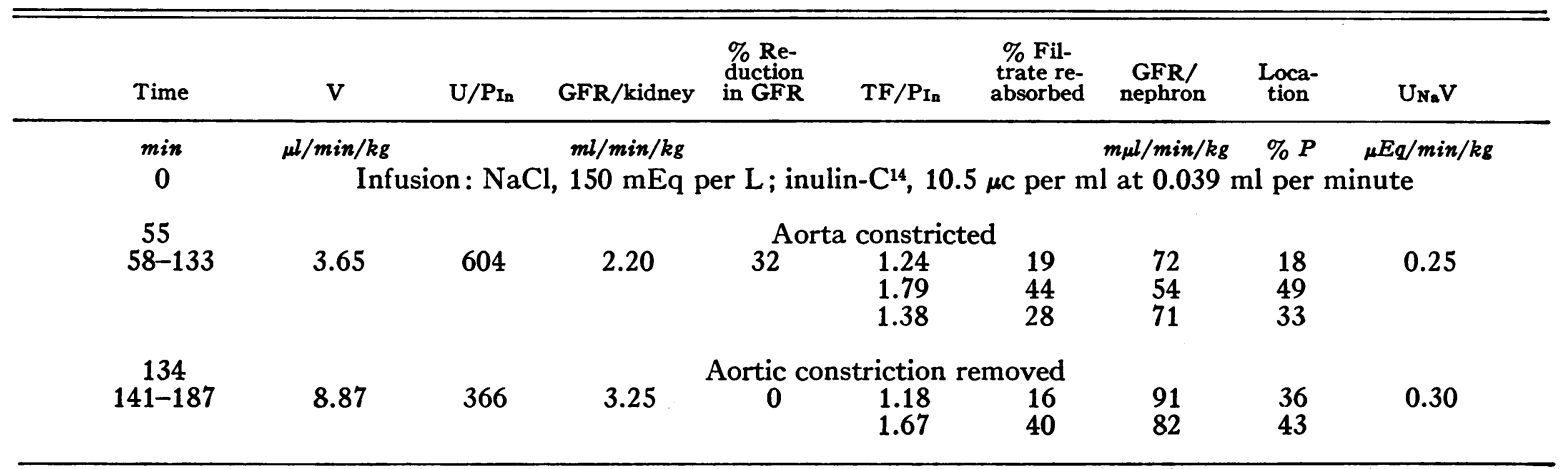




\section{Results}

Two experiments are shown in detail in Tables I and II to illustrate the two different protocols. In the first experiment, the aortic clamp was applied after control urine and tubular fluid collections had been obtained, whereas in the second ex- periment the clamp was applied before collections were begun. Comparable reductions in GFR per kidney were observed in the two experiments upon constriction of the aorta. In the experiment shown in Table II, GFR per nephron was also measured, and it can be seen that the values were lower dur-

TABLE III

The effect of acute reductions in GFR on filtrate reabsorption by the proximal tubule

\begin{tabular}{|c|c|c|c|c|c|c|c|c|c|c|c|}
\hline \multicolumn{6}{|c|}{ Control } & \multicolumn{6}{|c|}{ Aorta constricted } \\
\hline $\begin{array}{c}\text { Exp. } \\
\text { no. }\end{array}$ & $\underset{\text { kidney }}{\text { GFR/ }}$ & $\mathrm{TF} / \mathrm{P}_{\mathrm{In}_{\mathrm{n}}}$ & $\begin{array}{l}\% \text { Fil- } \\
\text { trate re- } \\
\text { absorbed }\end{array}$ & $\begin{array}{c}\text { GFR/ } \\
\text { nephron }\end{array}$ & $\begin{array}{c}\text { Loca- } \\
\text { tion }\end{array}$ & $\begin{array}{c}\text { GFR/ } \\
\text { kidney }\end{array}$ & $\begin{array}{l}\% \text { Re- } \\
\text { duction } \\
\text { in GFR }\end{array}$ & $T F / P_{I_{n}}$ & $\begin{array}{l}\text { \% Fil- } \\
\text { trate re- } \\
\text { absorbed }\end{array}$ & $\begin{array}{c}\text { GFR/ } \\
\text { nephron }\end{array}$ & $\begin{array}{c}\text { Loca- } \\
\text { tion }\end{array}$ \\
\hline & $\mathrm{ml} / \mathrm{min} / \mathrm{kg}$ & & & $\mathrm{mul} / \mathrm{min} / \mathrm{kg}$ & $\% P$ & $\mathrm{ml} / \mathrm{min} / \mathrm{kg}$ & & & & $m \mu l / m i n / k g$ & $\% P$ \\
\hline \multirow[t]{2}{*}{$1 *$} & 3.35 & 2.19 & 54 & 101 & 44 & 2.45 & 27 & 2.28 & 56 & 107 & 46 \\
\hline & & 1.72 & 42 & & 30 & 1.71 & 51 & 1.89 & 47 & 74 & 43 \\
\hline \multirow[t]{2}{*}{2} & 2.57 & 1.91 & 48 & 94 & 48 & 1.38 & 46 & 1.76 & 43 & 110 & 31 \\
\hline & & 2.33 & 57 & 126 & 40 & 1.42 & 45 & 2.14 & 53 & & 38 \\
\hline \multirow[t]{2}{*}{3} & 1.99 & 2.29 & 56 & 57 & 65 & 1.56 & 22 & 1.65 & 39 & 46 & 46 \\
\hline & & & & & & & & 1.53 & 35 & 50 & 32 \\
\hline \multirow[t]{4}{*}{4} & 2.08 & 1.55 & 36 & & 35 & 1.79 & 14 & 2.07 & 52 & & 44 \\
\hline & & & & & & & & 1.49 & 33 & & 31 \\
\hline & & & & & & 1.40 & 33 & 1.68 & 41 & & 45 \\
\hline & & & & & & & & 1.59 & 37 & & 45 \\
\hline \multirow[t]{3}{*}{$5 *$} & 3.25 & 1.18 & 16 & 91 & 36 & 2.20 & 32 & 1.24 & 19 & 72 & 18 \\
\hline & & 1.67 & 40 & 82 & 43 & & & 1.79 & 44 & 54 & 49 \\
\hline & & & & & & & & 1.38 & 28 & 71 & 33 \\
\hline \multirow[t]{5}{*}{ 6* } & 3.00 & 1.43 & 30 & 88 & 24 & 1.12 & 66 & 2.39 & 58 & 70 & 60 \\
\hline & & 2.83 & 64 & 96 & 62 & & & 3.70 & 73 & 27 & 64 \\
\hline & & & & & & 0.25 & 91 & 3.45 & 71 & 90 & 38 \\
\hline & & & & & & & & 4.57 & 78 & 61 & 49 \\
\hline & & & & & & & & 7.83 & 87 & 44 & 64 \\
\hline \multirow[t]{2}{*}{7} & 3.69 & 1.78 & 44 & & 59 & 2.63 & 29 & 1.55 & 35 & 50 & 59 \\
\hline & & & & & & & & 5.00 & 80 & 39 & 67 \\
\hline \multirow[t]{3}{*}{8} & 2.10 & 1.17 & 14 & 123 & 20 & 1.75 & 15 & 1.36 & 26 & 115 & 33 \\
\hline & & 1.41 & 30 & 123 & 23 & & & 2.06 & 51 & 94 & 56 \\
\hline & & & & & & 1.89 & 10 & 1.82 & 45 & 129 & 41 \\
\hline \multirow[t]{4}{*}{ 9* } & 1.94 & 1.68 & 40 & & 49 & 0.68 & 65 & 1.21 & 17 & 76 & 24 \\
\hline & & 2.32 & 57 & & 47 & & & 1.74 & 43 & 66 & 45 \\
\hline & & & & & & & & 2.11 & 53 & 99 & 45 \\
\hline & & & & & & & & 1.27 & 21 & 99 & 14 \\
\hline 10 & 1.46 & 1.98 & 49 & 97 & 44 & 1.26 & 14 & 1.55 & 35 & 81 & 31 \\
\hline \multirow[t]{2}{*}{11} & 1.34 & 1.49 & 33 & 70 & 27 & 0.72 & 46 & 3.41 & 71 & 58 & 54 \\
\hline & & 2.45 & 59 & 81 & 46 & & & & & & \\
\hline \multirow[t]{2}{*}{12} & 1.60 & 4.42 & 77 & 88 & 68 & 0.15 & 91 & 2.54 & 61 & 38 & 35 \\
\hline & & 2.79 & 64 & 86 & 60 & & & 5.52 & 82 & 44 & 51 \\
\hline \multirow[t]{4}{*}{13} & 1.11 & 2.17 & 54 & & 46 & 0.64 & 42 & 2.01 & 50 & & 51 \\
\hline & & 1.35 & 26 & & 27 & 0.75 & 32 & 2.13 & 53 & & 43 \\
\hline & & & & & & & & 1.83 & 45 & & 32 \\
\hline & & & & & & & & 1.49 & 33 & & 38 \\
\hline \multirow[t]{4}{*}{14} & 2.68 & 2.17 & 54 & 124 & 40 & & & & & & \\
\hline & 2.77 & 3.67 & 73 & 81 & 49 & & & & & & \\
\hline & & 1.70 & 41 & 104 & 31 & & & & & & \\
\hline & 3.66 & 1.97 & 49 & 128 & 48 & & & & & & \\
\hline 15 & 2.29 & 2.01 & 50 & & 42 & & & & & & \\
\hline \multirow[t]{2}{*}{16} & 2.54 & 2.11 & 53 & 131 & 40 & & & & & & \\
\hline & & 2.32 & 57 & 125 & 32 & & & & & & \\
\hline 17 & 2.84 & 1.34 & 25 & 96 & 23 & & & & & & \\
\hline & & 1.94 & 48 & 134 & 49 & & & & & & \\
\hline 18 & $\begin{array}{l}3.25 \\
1.34\end{array}$ & $\begin{array}{l}2.43 \\
2.72\end{array}$ & $\begin{array}{l}59 \\
63\end{array}$ & $\begin{array}{r}122 \\
87\end{array}$ & $\begin{array}{l}48 \\
56\end{array}$ & & & & & & \\
\hline & & 2.41 & 59 & 101 & 47 & & & & & & \\
\hline 19 & 1.28 & 1.89 & 47 & 132 & 47 & & & & & & \\
\hline & & 1.62 & 38 & 115 & 14 & & & & & & \\
\hline 20 & 1.51 & 1.75 & 43 & & 46 & & & & & & \\
\hline Mean & 2.33 & & & 103 & & 1.36 & & & & 72 & \\
\hline$\pm \mathrm{SD}$ & \pm 0.79 & & & \pm 20.7 & & \pm 0.68 & & & & \pm 25.8 & \\
\hline
\end{tabular}

* In these experiments, the aorta was first constricted and later released. 


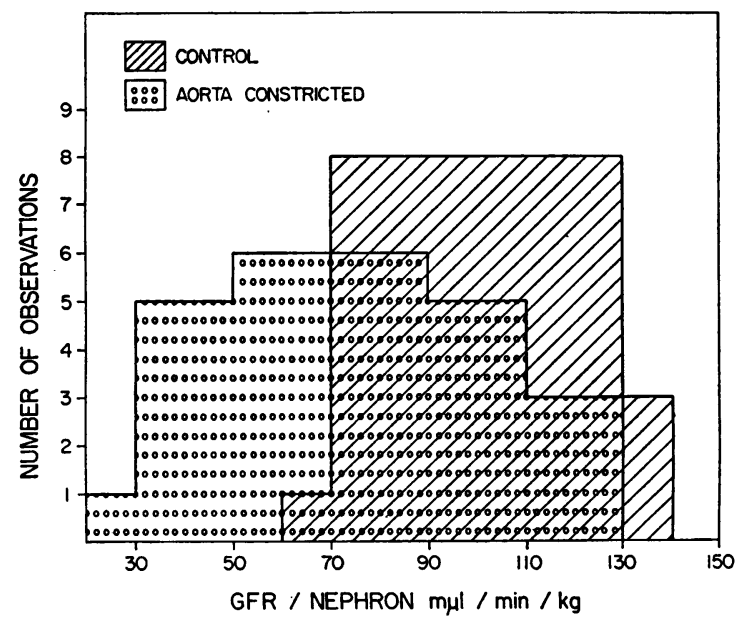

Fig. 1. GLomerular filtration Rate in INDividual NEPHRONS DURING CONTROL PERIODS AND DURING CONSTRICTION OF THE ABDOMINAL AORTA. Individual values have been grouped in increments of $20 \mathrm{~m} \mu \mathrm{l}$ per minute per $\mathrm{kg}$.

ing constriction than after the clamp was removed. In both experiments, sodium excretion was lower during the periods in which the aortic clamp was applied. Since the data of the 4 experiments carried out with the protocol shown in Table II were similar to those of the other experiments, no distinction is made between the two protocols in the succeeding Figures and Table.

In Table III are shown GFR per kidney, TF/ $P_{\text {In }}$ values, calculated per cent filtrate reabsorbed, and GFR per nephron for all experiments. The mean GFR per kidney for the control periods was $2.33 \mathrm{ml}$ per minute per $\mathrm{kg} \pm 0.79 \mathrm{SD}$, whereas the mean during constriction of the aorta was $1.36 \mathrm{ml}$ per minute per $\mathrm{kg} \pm 0.68 \mathrm{SD}$.

Upon constriction of the aorta, the entire kidney was noted to shrink in size. When viewed under the microscope, the lumina of individual tubules became narrower, but we did not observe complete occlusion of lumina, and tubular fluid could be collected without difficulty. In Figure 1 all the values for GFR per nephron are shown, grouped in increments of $20 \mathrm{m \mu l}$ per minute per kg. The range during the control periods was from 57 to $134 \mathrm{~m} \mu \mathrm{l}$ per minute per $\mathrm{kg}$ with a mean of $103 \mathrm{~m} \mu \mathrm{l}$ per minute per $\mathrm{kg} \pm 20.7 \mathrm{SD}$. During constriction of the aorta, the range was from 27 to 129 with a mean of $72 \mathrm{~m} \mu \mathrm{l}$ per minute per $\mathrm{kg} \pm$ $25.8 \mathrm{SD}$. Although there was considerable overlap between control and clamped periods, in individual experiments a fall in GFR per nephron was usually observed when the aorta was constricted. We conclude from these observations, therefore, that acute constriction of the aorta reduced filtration rate by a general decrease throughout all nephrons and not by complete loss of function in some nephrons leaving the remainder intact.

In Figure 2, all the values for per cent filtrate reabsorbed for both control and experimental periods are plotted on the ordinate, and the corresponding location along the proximal tubule is shown on the abscissa. It can be seen that with reductions in GFR of up to $66 \%$, fractional reabsorption of the glomerular filtrate remained essentially the same as under control conditions. The linear regression equations, if we assume for the purpose of statistical evaluation that per cent reabsorption is approximately linear over this limited segment of the nephron, are $y=11.1+0.86 x$ for the control data and $y=4.3+0.96 x$ for the experimental data (the five highest points observed at $>90 \%$ GFR reduction were omitted from this calculation). The $95 \%$ confidence limits for the control slope of 0.86 are \pm 0.21 ; thus the slope of 0.96 for the experimental data falls within these limits. The best approximation of filtrate reab-

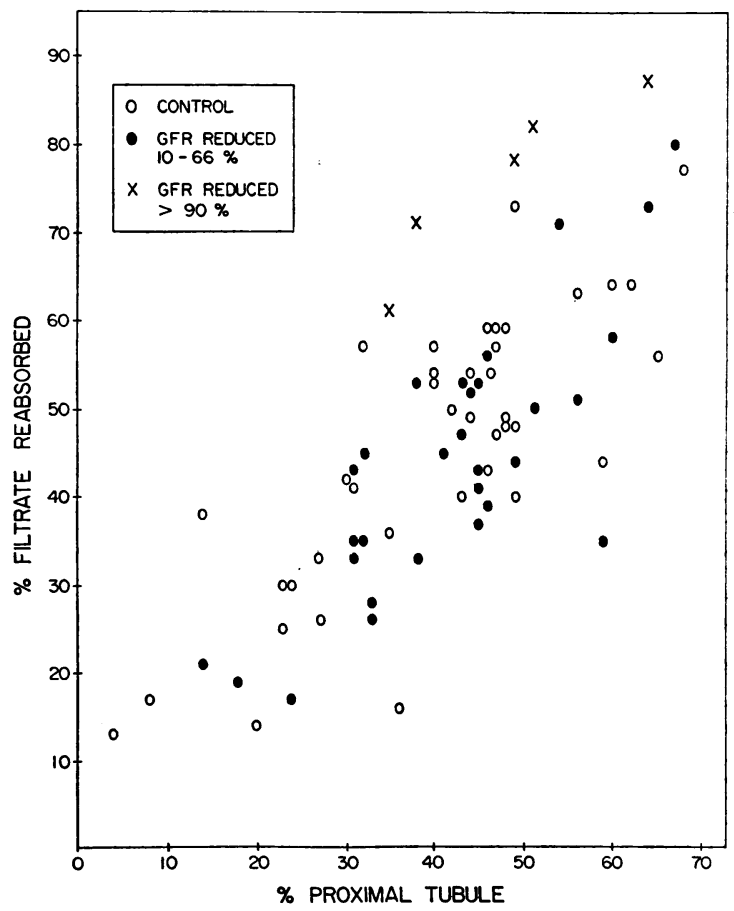

Fig. 2. Fractional Reabsorption OF the gLOMERULAR FILTRATE WITH AND WITHOUT CONSTRICTION OF THE ABDOMINAL AORTA. 


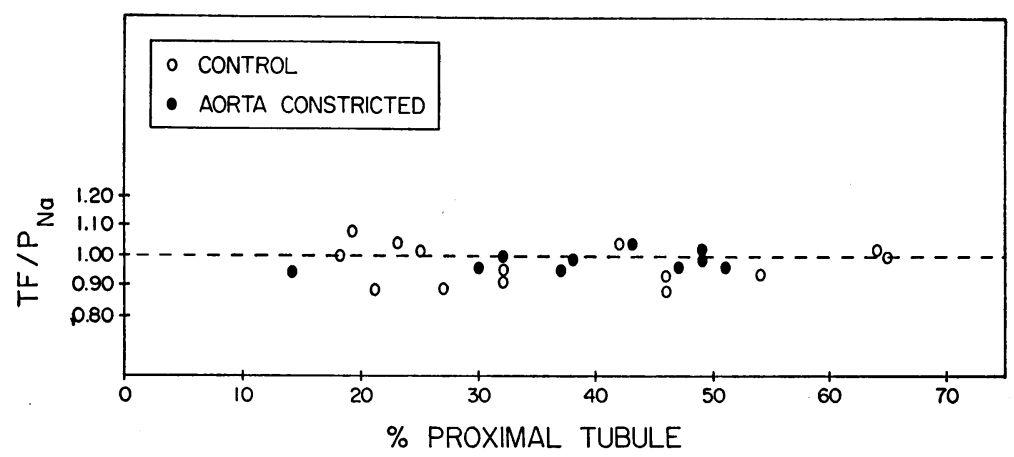

Fig. 3. Tubular fluid to plasma sodium concentration Ratios (TF/ $\left.\mathrm{P}_{\mathrm{Na}}\right)$ WITH AND WITHOUT CONSTRICTION OF THE AORTA.

sorbed at $65 \%$ of the proximal tubular length, calculated from the two regression equations, is $67 \%$ in the control and $66.7 \%$ in the experimental periods. We conclude from these observations that the fraction of the glomerular filtrate reabsorbed by the proximal tubules was not significantly altered by reductions in GFR ranging from 10 to $66 \%$. In two experiments in which GFR was reduced by a greater per cent (over $90 \%$ ) fractional reabsorption was definitely increased.

In Figure 3, the $T F / \mathrm{P}_{\mathrm{Na}}$ ratios are shown for the control and clamped collections. The mean ratio during control periods was $0.98 \pm 0.05 \mathrm{SD}$ and during constriction of the aorta was $0.98 \pm$ $0.03 \mathrm{SD}$. There was evidently no tendency for a transtubular sodium concentration gradient to develop in the accessible portion of the proximal tubule. Thus, any decrease in the supply of sodium to successive segments of the proximal tubule was due to changes in tubular fluid flow rather than sodium concentration.

In all experiments, sodium excretion was less than $1 \%$ of the filtered sodium load during both control and clamped periods. Excretion rate fell in each case with constriction of the aorta. ${ }^{2}$

\section{Discussion}

There is abundant evidence that sodium reabsorption by the proximal tubule occurs by active transport, but the nature of its regulation is obscure. It is apparent from several studies that the

2 Because of the very low sodium excretion rates, we have not attempted to analyze changes in excreted fraction with constriction of the aorta or to compare the per cent fall in sodium excretion with that in GFR, as has been done in the dog (10). supply of sodium to the tubules influences the rate of its reabsorption. Thus under conditions of normal GFR and plasma sodium concentration, approximately $65 \%$ of filtered sodium is reabsorbed in the first two-thirds of the proximal tubule $(4-6)$. In the rat, when filtered load is increased almost twofold by hypertonic saline infusion, the fraction of filtered sodium and water reabsorbed in the proximal tubule remains essentially the same $(7,8)$. Despite this inherent capacity for enhanced reabsorption, some feature of proximal transport appears to prevent the complete reabsorption of sodium when the filtered load is reduced. This is evident in clearance studies in dogs where filtration rate was reduced by as much as $40 \%$ without entirely eliminating sodium from the urine (10). The present studies provide direct information on proximal sodium reabsorption under conditions of diminished filtered loads. The data demonstrate that fractional sodium and water reabsorption remains at about $65 \%$ of the filtered load in the accessible proximal tubule, even with reductions in GFR up to $66 \%$. It would seem, therefore, that with both acute increases and decreases in filtered loads of sodium, corresponding increases and decreases in reabsorptive rates for sodium occur in the proximal tubule. These observations provide strong evidence that proximal sodium transport is regulated to an important degree by the rate of delivery of sodium to the sites of active transport.

The consequences of constant fractional reabsorption by the proximal tubules on the load of sodium delivered to more distal sites can be appreciated from a calculation of the absolute amounts of sodium involved. With a normal serum sodium 
concentration of $140 \mathrm{mEq}$ per $\mathrm{L}$ and a GFR of $5.0 \mathrm{ml}$ per minute per $\mathrm{kg}, 700 \mu \mathrm{Eq}$ of sodium is filtered per minute, and approximately $245 \mu \mathrm{Eq}$ remains at the end of the accessible portion of the proximal tubule. When GFR is reduced by $50 \%$, so that only $350 \mu \mathrm{Eq}$ of sodium is filtered per minute, $123 \mu \mathrm{Eq}$ remains in the tubular fluid at $65 \%$ of proximal tubular length. Thus, a difference of $350 \mu \mathrm{Eq}$ filtered at the glomerulus is reduced to a difference of only $123 \mu \mathrm{Eq}$ as the end of the proximal tubule is approached. The effect of the fall in filtration rate is therefore blunted by the adaptive reduction in proximal salt transfer. This pattern of reabsorption by the proximal tubule helps to account for the continued delivery of sodium to more distal segments of the nephron when GFR is reduced. Whether proximal tubular flow is exponential, as first suggested by Walker, Bott, Oliver, and MacDowell (15), or linear, constant fractional reabsorption would be an important factor in maintaining the supply of sodium to the distal nephron.

The mechanism that accounts for the adjustments in rate of proximal sodium and water transfer in response to changes in filtered load is unknown, but several possibilities may be considered. First, it is evident from the $\mathrm{TF} / \mathrm{P}_{\mathrm{Na}}$ ratios in Figure 3 that a transtubular concentration gradient does not develop and that changes in tubular fluid sodium concentration cannot account for the reduction in rate of sodium reabsorption that occurred in these experiments. Kelman has suggested that proximal sodium and water reabsorption is formally analogous to a catalytic flow reactor system (16). The underlying principle of this physical model is that cross-sectional mixing of fluid in a tube is incomplete at slow flow rates but more nearly complete at rapid flow rates. As applied to the renal tubule, the concentration of sodium at the luminal membrane would vary directly with tubular fluid flow rate, and this peripheral concentration would regulate the entry of sodium into the lining epithelial cells. However, Robinson has concluded from a mathematical analysis of the relation between tubular dimensions and flow rates that heterogeneity of fluid within the cross-sectional area of the tubule is highly unlikely (17). Another possibility is that the surface area of the luminal membrane changes as a function of flow rate. The diameter of the proximal tubule has been observed to increase during hypertonic saline infusion (7), and in the present study we observed a narrowing of the tubular lumen upon constriction of the aorta. Thus, the number of sites available for entry of sodium into the epithelial cells might vary with changes in tubular flow. Finally, acute constriction of the aorta might stimulate release of renin from the juxtaglomerular cells (18). This could increase the concentration of angiotensin II within the proximal lumen, leading to a reduction in sodium and water transport by this segment $(19,20)$.

Some comment is indicated concerning the applicability of the present findings to other species. In the dog, reductions in GFR of over $50 \%$ induced by clamping one renal artery have been reported to increase $T F / P_{\text {In }}$ ratios in the middle third of the proximal tubule (21). Presumably, the absolute rate of sodium and water transfer did not decrease in proportion to the fall in GFR. More recently, Dirks, Cirksena, and Berliner (22) have reported that during saline diuresis in the $\mathrm{dog}$, proximal $\mathrm{TF} / \mathrm{P}_{\mathrm{In}}$ ratios are lower than under nondiuretic conditions, but are not further altered when GFR is then reduced. Apparently, although there are some species differences, the filtered load has some influence on proximal sodium transport in the dog. Some of the observed differences between rats and dogs might be related to the range of filtered sodium over which normal glomerulotubular balance obtains in the two species. In the rat, massive loading with isotonic saline (23), and in some instances with hypertonic saline (7), leads to a decrease in fractional reabsorption of sodium and water. Conversely, we observed in the present study that fractional reabsorption of sodium and water increases when GFR is reduced by as much as $90 \%$. Thus in the rat, there seem to be limits beyond which the proportionality between filtered load and proximal reabsorption no longer is present. It may be that in the dog and perhaps in certain other species, the range over which normal glomerulotubular balance exists is narrower than in the rat.

\section{Summary}

The effect of acute reductions in glomerular filtration rate (GFR) on sodium and water transfer by the proximal tubule was studied in rats by micropuncture methods. GFR was reduced by con- 
striction of the abdominal aorta above the origin of the renal arteries. It was found that with reductions ranging between 10 and $66 \%$, the fraction of filtered sodium and water reabsorbed by the proximal tubules remained essentially the same as under control conditions. This indicates that the absolute rate of net sodium and water transfer decreased in direct proportion to the fall in GFR. Since proximal sodium concentration did not change with constriction of the aorta, the decreased rate of transport was apparently the result of diminished delivery of sodium to the sites of active transport. These observations support the view that proximal sodium reabsorption is regulated to a large degree by flow-dependent kinetics.

\section{References}

1. Windhager, E. E., and G. Giebisch. Micropuncture study of renal tubular transfer of sodium chloride in the rat. Amer. J. Physiol. 1961, 200, 581.

2. Windhager, E. E., and G. Giebisch. Comparison of short-circuit current and net water movement in single perfused proximal tubules of rat kidneys. Nature (Lond.) 1961, 191, 1205.

3. Giebisch, G., R. M. Klose, G. Malnic, W. J. Sullivan, and E. E. Windhager. Sodium movement across single perfused proximal tubules of rat kidneys. J. gen. Physiol. 1964, 47, 1175.

4. Lassiter, W. E., C. W. Gottschalk, and M. Mylle. Micropuncture study of net transtubular movement of water and urea in non-diuretic mammalian kidney. Amer. J. Physiol. 1961, 200, 1139.

5. Gottschalk, C. W. Renal tubular function: lessons from micropuncture. Harvey Lect. 1963, series 58, 99.

6. Clapp, J. R., J. F. Watson, and R. W. Berliner. Osmolality, bicarbonate concentration, and water reabsorption in proximal tubule of the dog nephron. Amer. J. Physiol. 1963, 205, 273.

7. Giebisch, G., R. M. Klose, and E. E. Windhager. Micropuncture study of hypertonic sodium chloride loading in the rat. Amer. J. Physiol. 1964, 206, 687.

8. Lassiter, W. E., M. Mylle, and C. W. Gottschalk. Net transtubular movement of water and urea in saline diuresis. Amer. J. Physiol. 1964, 206, 669.
9. Thompson, D. D., and R. F. Pitts. Effects of alterations of renal arterial pressure on sodium and water excretion. Amer. J. Physiol. 1952, 168, 490.

10. Davidson, D. G., N. G. Levinsky, and R. W. Berliner. Maintenance of potassium excretion despite reduction of glomerular filtration during sodium diuresis. J. clin. Invest. 1958, 37, 548.

11. Stein, R. M., D. D. Bercovitch, and M. F. Levitt. Dual effects of saline loading on renal tubular sodium reabsorption in the dog. Amer. J. Physiol. 1964, 207, 826.

12. Bank, N. Relationship between electrical and hydrogen ion gradients across rat proximal tubule. Amer. J. Physiol. 1962, 203, 577.

13. Marsh, D. J., and C. S. Frasier. The reliability of inulin for determining volume flow in rat renal cortical tubules. Amer. J. Physiol., in press.

14. Malnic, G., R. M. Klose, and G. Giebisch. Micropuncture study of renal potassium excretion in the rat. Amer. J. Physiol. 1964, 206, 674.

15. Walker, A. M., P. A. Bott, J. Oliver, and M. C. MacDowell. The collection and analysis of fluid from single nephrons of the mammalian kidney. Amer. J. Physiol. 1941, 134, 580.

16. Kelman, R. B. A theoretical note on exponential flow in the proximal part of the mammalian nephron. Bull. Math. Biophys. 1962, 24, 303.

17. Robinson, J. R. Reflections on Renal Function. Springfield, Ill., Charles C Thomas, 1954, pp. 83-87.

18. Davis, J. O. Two important frontiers in renal physiology. Circulation 1964, 30, 1.

19. Gertz, K. H. Direct measurement of the transtubular flux of electrolytes and nonelectrolytes in the intact rat kidney in Proceedings of the 22nd International Congress on Physiological Sciences. Leiden, Excerpta Medica Foundation, 1962, p. 370.

20. Leyssac, P. P. The in vivo effect of angiotensin on the proximal tubular reabsorption of salt in rat kidneys. Acta physiol. scand. 1964, 62, 436.

21. Watson, J. F. Micropuncture study of the effect of reduced GFR on $\mathrm{K}$ and water reabsorption in proximal tubule of the dog kidney (abstract). Clin. Res. 1964, 12, 204.

22. Dirks, J. H., W. J. Cirksena, and R. W. Berliner. The effect of saline on sodium reabsorption by the proximal tubule of the dog. Fed. Proc. 1965, 24, 520.

23. Cortney, M. A., M. Mylle, and C. W. Gottschalk. Renal water and solute reabsorption in isotonic saline loaded rats. Physiologist 1964, 7, 108. 